\title{
Reading the Concept Map of Physics Teacher Candidates: A Case of Light
}

\author{
Necla Dönmez Usta ${ }^{1}$, Eser Ültay ${ }^{2 *}$, Neslihan Ültay² \\ ${ }^{1}$ Department of Computer Education and Educational Technology, Faculty of Education, Giresun University, Giresun, Turkey, ${ }^{2}$ Department of \\ Elementary Education, Faculty of Education, Giresun University, Giresun, Turkey
}

*Corresponding Author: eserultay@gmail.com

\section{ABSTRACT}

The aim of this study was to determine the ability of physics teacher candidates' to read a concept map previously prepared by the researchers about a light topic and then convert the concept map into the appropriate text. The study was carried out in the form of case study method in a Turkish University in the Black Sea Region with 32 physics teacher candidates in the 2016-2017 academic years. To collect data, the concept map about light was given to the physics teacher candidates and they were asked to convert this concept map into meaningful text. The meaningful texts that teacher candidates tried to transform according to the concept map were evaluated according to a reference text. The reference text was prepared by experts. When the findings obtained from the study were examined in general, it was concluded that $78.123 \%$ of these physics teacher candidates could read the concept map related to light subjects and concepts at medium level. According to the results of this study, it is recommended that studies related to reading concept maps should be studied for different subjects and concepts.

KEY WORDS: concept map; light; physics teacher candidates; reading concept map

\section{INTRODUCTION}

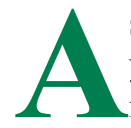

$\mathrm{s}$ in every field, developments in education in recent years have made some changes mandatory. One of the most important of these changes is the focus of teaching on concepts because research has been shown that students may be able to solve very complex science problems but they may not be able to explain the concepts (Case and Fraser, 1999; Masson and Vazquez-Abad, 2006; Dönmez Usta and Ültay, 2015; Ültay and Can, 2015; Ültay, 2017). This situation has led to a focus of teaching on the teaching of concepts and at the same time has given rise to new fields of study about how concept teaching should be done effectively. One of the results of this effort has seen an increase in the learning of concept teaching with concept maps. Concept maps are two-dimensional diagrams showing the concepts about a topic and relationships between concepts. In other words, concept maps are concretized through schemas of people's knowledge on a particular subject (Kaya, 2003). Kaptan (1998) explained concept maps as a learning-teaching strategy that shows a bridge between how people realize learning and meaningful learning.

When the use of concept maps in science education is examined, it is seen that concept maps are preferred for various purposes. They have been used to improve students' conceptual learning and to increase their success (e.g., Okebukola, 1990; Güneş et al., 2006) as well as they are also frequently used in the evaluation of conceptual understandings (e.g., Şahin, 2002; Kaya and Ebenezer, 2003). The concept maps of Uzuntiryaki and Geban (1998) and Uzuntiryaki et al. (2001) were used to improve the conceptual learning of their students. According to Novak and Gowin (1984), concept maps are one of the most powerful evaluation tools that investigate conceptual learning changes in cognitive structure. Concept maps have been referred to as a "conceptual graph" for conceptual learning (Wu, 2007). Concept maps are one of the most powerful graphical tools for knowledge acquisition (Shieh and Yang, 2014). It has been ragued that concept maps could be a key for observing conceptual learning and the deep understanding that students are gaining (Vodovozov and Raud, 2015). Thanks to concept maps, educators or teachers are able to quickly observe the improvements in conceptual learning based on the knowledge, understanding, and problemsolving ability of their students (Kilic and Cakmak, 2013). For instance, linkages are drawn between two unrelated concepts could expose students' conceptual learning. The concept maps used by Horton et al. (1993), Bayram et al. (1999), Sarıçayır (2000), and Öztürk (2003) increased the success of their students. Regardless of the purpose, students need to be taught how to draw concept maps (Kaya, 2003; Dönmez Usta and Ültay, 2016). Although the level of education that students need to draw a concept map can vary according to age and level, it has been reported that 3-4 h is needed for university students (Kaya and Ebenezer, 2003). This is a very time-consuming education for students (Chang et al., 2002).

There have been many tools developed to document and analyze changes in cognitive structure. One of the most important of these tools is the concept map (Novak and Gowin, 1984). Concept maps can be created based on the strategies 
developed by Novak and Gowin (Şahin, 2002) or using different techniques. Turan (2016) summarized these methods as novak, numbering, and gap filling type. The gap filling type has two versions which are conceptual and relationship. It was noted that problems do arise in the Turkish application of the Novak type (Bağc1, 2003; Turan, 2016). However, given the advantages provided by concept maps, it is understood why it is preferred despite these problems.

When the literature is examined, it is seen that three different methods are used to evaluate concept maps. The first one is the evaluation of the concept map as content (White and Gunstone, 1992). In this method, link words or propositions are given one point, five points for placement according to hierarchy, ten points for cross-links, and one point for each example (Kaya, 2003; Bak and Ayas, 2008). In the second approach, an expert or the teacher who prepared the map creates a reference map in accordance with the first approach, and then the map drawn by the student is compared with this reference map (Bak and Ayas, 2008). The third approach is a combination of the first two approaches. First, the expert or the teacher creates a reference concept map and scores it according to the first approach, then the student's score is calculated according to the score of this reference concept map and the total score is calculated (Bak and Ayas, 2008; Dönmez Usta and Ültay, 2016; Turan, 2016). This study aimed to determine if the student teachers were able to read a concept map based on light and then convert this into appropriate text.

The subject of light has been the subject of much research in terms of abstract concepts. One of the most important reasons for this is the excess of alternative concepts that students have in this regard (Maurines, 1993; Wittmann et al., 2003; Çil, 2010). For example, it has been reported that students have difficulty in understanding the concept of light, diffusion of light, vision and image formation, as well as many alternative conceptions of these topics (Osborne et al., 1990; Büyükkasap and Samanc1, 1998; Toh and Boo, 1999). Considering that concept maps not only embodies the concepts students have but also the relationships between concepts, it is thought that the concept of light taught through concept maps and the reinforcement or evaluation of this information would be very effective in terms of students' conceptual learning.

The aim of this study was to determine the ability of physics teacher candidates' to read a concept map previously prepared by researchers about a light topic and then convert the concept map into appropriate text.

\section{METHODOLOGY}

\section{Research Design}

This study was suitable for a case study because it was conducted to elucidate a situation and to make evaluations and it was done to investigate the characteristics of the sample group (Çepni, 2005). One of the most important features of this method is that one aspect of the research problem can be studied in depth and in a short time. The most important advantage of this method is that it gives the opportunity to concentrate on a particular situation of a problem (Wellington, 2000; Çepni, 2007).

\section{Research Group}

In this study, the reason for choosing the case study method was to conduct the study in a state university in the Black Sea Region with 32 physics teacher candidates in the 2016-2017 academic year and to determine whether these teacher candidates could convert a concept map prepared by experts in light to text. Twenty of the 32 teacher candidates were female, 12 were male, and the teacher candidates' ages ranged from 22 to 32 . To differentiate the participants in this study, the teacher candidates who participated in this research within the framework of research ethics were coded as T1, T2, T3,.., T32.

\section{Data Collection Tool}

To collect data, the concept map about the subject of light from Fencebilim (2016) was taken, after making the necessary minor arrangements by the researchers, 32 physics teacher candidates were asked to convert this concept map into meaningful text. The texts from these teacher candidates were evaluated according to a reference text. Figure 1 is both the concept map that was given to the teacher candidates and the reference text that was prepared by the experts used for scoring the teacher candidates' texts.

\section{Data Collection}

To determine the ability of physics teacher candidates to convert a concept map prepared by the researchers, they were asked to convert a concept map related to light into meaningful text. These teacher candidates were provided instruction in creating concept maps by the first researcher for 2 weeks using four-course hours $(4 \times 50=200 \mathrm{~min})$ to prepare them for this study. In addition, information was given about how to create concept maps with different approaches and critical points of creating concept maps. Two weeks after the class discussion, teacher candidates were given a concept map about the subject of light, which was edited and finalized by the researchers, and they were asked to convert this concept map into meaningful text within a class hour (50 min).

It was taken under consideration that these teacher candidates had completed their undergraduate education in physics and/ or departments related to physics. Therefore, they had taken several physics courses before, and they may have more theoretical knowledge about the subject that was included in the concept map. For this reason, it was anticipated that while converting the concept map into a meaningful text, some student teachers may include theoretical information beyond the scope of the concept map providing data that exceeded the purpose of the study. To address this issue, teacher candidates were especially instructed by the first researcher to create their text using only the information provided in the current concept map.

\section{Data Analysis}

As stated, there are three different approaches to assess concept maps (Kaya, 2003). The first one is to evaluate the 


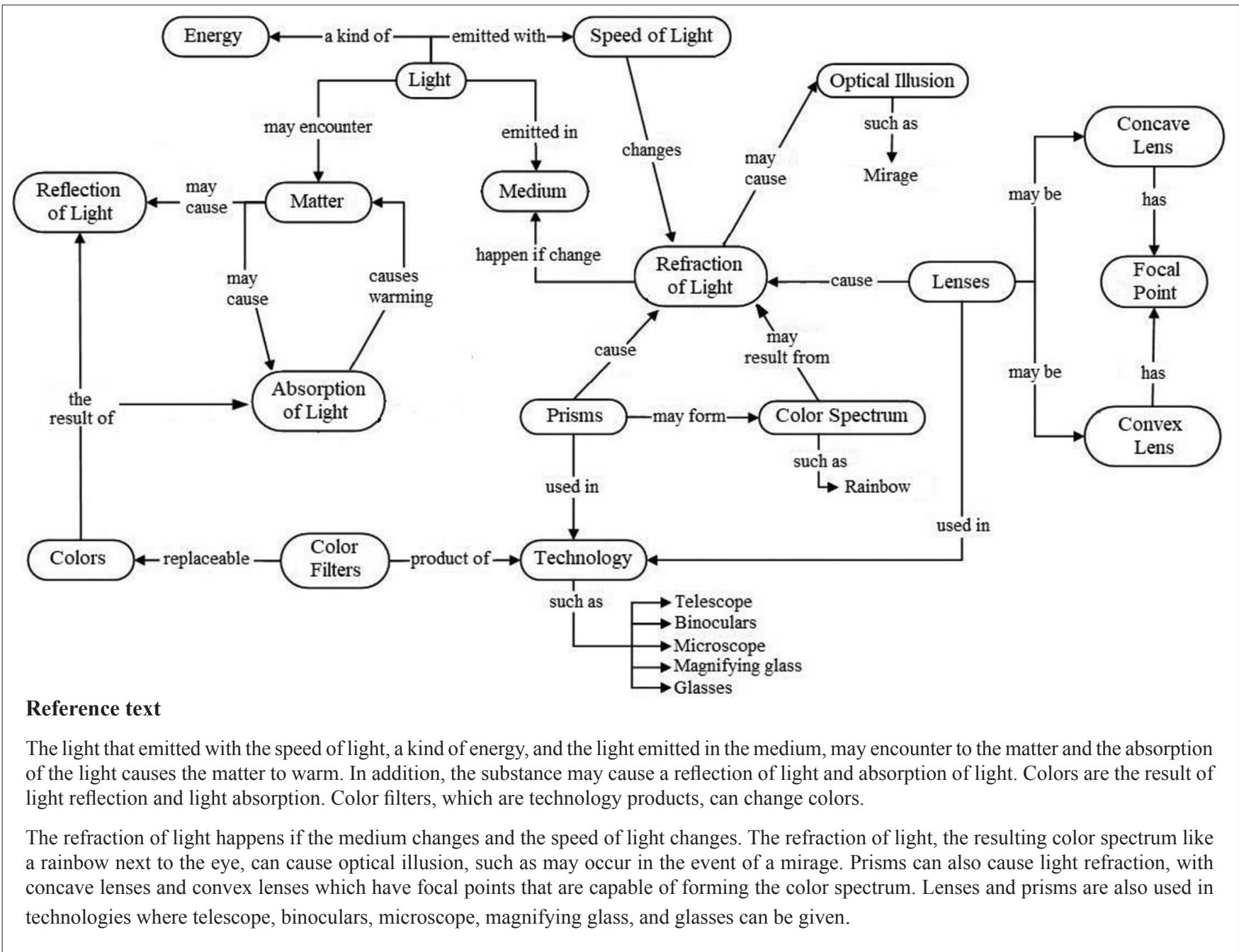

Figure 1: Concept map which was given to the teacher candidates and the reference text prepared by the experts used for scoring the teacher candidates' texts

content of concept maps (White and Gunstone, 1992). In this evaluation approach, four criteria have been identified such as propositions (one point), placement according to hierarchy stage (five points), cross-links (10 points), and examples (one point) (Kaya, 2003; Bak and Ayas, 2008). In the second approach, an expert or the teacher who prepared the map creates a reference map in accordance with the first approach, and the map drawn by the student is compared with this reference map (Bak and Ayas, 2008). The third approach is a combination of the first two approaches. First, the expert or the teacher creates a reference concept map and scores as in the first approach, then the student's score is calculated according to the score of this reference concept map and the total score is calculated (Bak and Ayas, 2008; Dönmez Usta and Ültay, 2016; Turan, 2016). In this study, when the concept map was examined, it was seen that there was no hierarchy. Therefore, this step has not been taken into account when scoring. According to the criteria (one point), cross-links (10 points) and samples (one point), it was determined that the maximum score that could result from converting the concept map into meaningful text was 40 . After evaluating the meaningful texts formed by teacher candidates according to these criteria, statistical data were obtained and necessary comments were made on this data. Based on the arithmetic average (27.28) of teacher candidates' scores, they were categorized according to the standard deviation (9.94). These categories are given in Table 1.

\section{Quality in the Research}

The reference concept map text of the study was developed and scored by the researchers. However, to ensure the reliability of the comparative agreement between the two raters, it was requested that a different field education expert evaluate the data, then the results of the researchers were compared with the results of IBM SPSS v.22 and Cohen's Kappa Coefficient was calculated. The calculated Cohen's Kappa ( $\kappa)$ was found to be 0.89, and it was observed that Landis and Koch (1977) classifications were almost perfect. After this stage, the researchers evaluated the concept maps. The expert was an active faculty member with 11 years of academic experience, and his expertise area is context-based learning approach and conceptual learning. 
In addition, a language expert had checked the developed reference concept map text in terms of grammar and comprehensibility. After the necessary final arrangements were made, the reference text was finalized. This language expert was a professor who had 17 years of academic experience and was an expert and actively working in the field of new Turkish literature.

Before the data collection process started, teacher candidates were provided with information such as "these data will not be used as an assessment for your lessons," and "data will be used for research purposes only." The purpose of this information was to improve the credibility of teacher candidates in this process by making them comfortable and transparent. In addition, to increase the credibility and consistency of the study, data were evaluated twice at different times and places during the analysis of texts developed by teacher candidates.

In non-quantitative research, it is possible to transfer the results of the research rather than the generalization of the research results (Yıldırım and Şimşek, 2011; Creswell, 2013). In this study, data obtained to increase the transferability are presented. Miles and Huberman (1994) highlighted that results should be supported by data. This is an indication of the confirmability. In this research, some parts of the meaningful texts of the teacher candidates are presented in the results to support discussion and conclusions.

\section{Ethics in the Research}

First, consent for research publication to include some data of the teacher candidates who were included in this study was obtained. In addition, it was stated that while some demographic information of the teacher candidates may be published it was highlighted that they would in no way be identified in the data and no harm would come to them because of participation in this study (Cohen and Manion, 1989; Drew et al., 1996). As a result, teacher candidates who participated

\begin{tabular}{lc}
\hline $\begin{array}{l}\text { Table 1: Teacher candidates' categories and their points } \\
\text { range }\end{array}$ \\
\hline Categories & Points range \\
\hline Weak & $0-17.34$ points \\
Medium & $17.34-37.22$ \\
Good & $37.22-40$ \\
\hline
\end{tabular}

in the research within the framework of research ethics were coded as $\mathrm{T} 1, \mathrm{~T} 2, \mathrm{~T} 3, \ldots, \mathrm{T} 32$.

\section{FINDINGS AND DISCUSSION}

This section of the study includes the findings and the discussion based on the findings. The scores of the physics teacher candidates, according to the reference text, are presented in Table 2.

The arithmetic average, the highest, the lowest scores, and the standard deviations of the scores of the physics teacher candidates were calculated by the IBM SPSS v22 package program and presented in Table 3.

As shown in Table 3, the arithmetic average of the points received by the teacher candidates was 27.28. The standard deviation of the scores was 9.94. The lowest score was 2 and the highest score was 39 . The text of T23 which had the highest score according to the reference text is presented in Figure 2.

As evident in Figure 2, the native language of the teacher candidate was Turkish, T23's reference text has been translated into English for this article:

Lenses and prisms can cause light refraction. Lenses can be thin and thick-edged. Thin and thick-edged lenses have focal points. Prisms can be used in technology, for example, telescope, binoculars, microscope, magnifying glass, and glasses. Lenses are also used in technology. Lenses can also form the color spectrum. The color spectrum may occur as a result of the refraction of light such as rainbow. The refraction of light can cause an optical illusion, for example, mirage. Light speed changes with light refraction. If the medium changes, the light is refracted. Light is emitted in the medium. Light is a kind of energy. The matter may encounter with light. Matter may cause light absorption. Light absorption may cause the matter warms. Matter may cause a reflection of light. Colors occur as a result of absorption and reflection of light. Color filters can change the colors. Color filters are the products of technology.

Considering that the highest score that could be achieved according to the reference text was 40 points, 39 points achieved by T23 indicates they were able to read the concept map. This situation could be explained by the fact that physics teacher candidates can read the concept map correctly and can understand the concept map correctly. In addition, the fact that

\begin{tabular}{|c|c|c|c|c|c|c|c|}
\hline Teacher candidates & Score & Teacher candidates & Score & Teacher candidates & Score & Teacher candidates & Score \\
\hline $\mathrm{T} 1$ & 28 & T9 & 35 & T17 & 17 & $\mathrm{~T} 25$ & 12 \\
\hline $\mathrm{T} 2$ & 27 & $\mathrm{~T} 10$ & 37 & $\mathrm{~T} 18$ & 33 & $\mathrm{~T} 26$ & 26 \\
\hline $\mathrm{T} 3$ & 6 & T11 & 36 & T19 & 23 & $\mathrm{~T} 27$ & 37 \\
\hline $\mathrm{T} 4$ & 19 & $\mathrm{~T} 12$ & 29 & $\mathrm{~T} 20$ & 35 & $\mathrm{~T} 28$ & 36 \\
\hline T5 & 37 & $\mathrm{~T} 13$ & 32 & $\mathrm{~T} 21$ & 35 & T29 & 29 \\
\hline T6 & 36 & $\mathrm{~T} 14$ & 31 & $\mathrm{~T} 22$ & 12 & $\mathrm{~T} 30$ & 2 \\
\hline $\mathrm{T} 7$ & 22 & $\mathrm{~T} 15$ & 35 & $\mathrm{~T} 23$ & 39 & $\mathrm{~T} 31$ & 30 \\
\hline $\mathrm{T} 8$ & 11 & $\mathrm{~T} 16$ & 34 & $\mathrm{~T} 24$ & 26 & $\mathrm{~T} 32$ & 26 \\
\hline
\end{tabular}


the physics teacher candidates were able to read the concept map correctly which may be related to the adequate level of field information associated with the subject of light. Sufficient knowledge of the relevant field is expected to allow the teacher candidates to read the concept map almost correctly.

The text belonging to T30, which received the lowest score, is presented in Figure 3.

Similar to T23 this has also been translated into English for this article:

The refraction of light occurs when the light changes direction as it passes through different environments. Color spectrum occurs as a result of light rays refracting from the prism. When we drop the color of the light onto the color filter, we have the ability to observe the resulting colors. Colors occur as a result of absorption of light. The lenses are also transparent media with at least one surface spherical. Light prism is a transparent environment consisting of triangular surfaces.

Considering that this physics teacher candidate obtained only two points, it can be stated they were barely able to read the concept map. In this case, it can be interpreted that the teacher candidate prioritized the existing field information rather than reading the concept map. Although the direction concepts did not exist in the concept map, the fact that the teacher candidate made such an introduction supports this interpretation. In addition, the teacher candidate wrote that:

We have the ability to observe the colors that occur when we drop the colors of the light onto the colored filter. The lenses are also transparent media with at least one surface

\section{Table 3: Distribution of scores of physics teacher candidates}

\begin{tabular}{ccccc}
\hline $\mathbf{n}$ & Lowest score & Highest score & $\begin{array}{c}\text { Arithmetic } \\
\text { average }\end{array}$ & $\begin{array}{c}\text { Standard } \\
\text { deviation }\end{array}$ \\
\hline 32 & 2 & 39 & 27.28 & 9.94 \\
\hline
\end{tabular}

spherical. Light prism is a transparent environment consisting of triangular surfaces.

These statements clearly showed that they interpreted the concept map based on the field information. In the implementation process of the study, teacher candidates were warned by the researchers, although they were asked to create a text within the scope of the current concept map. This situation can be explained by the fact that the teacher could not read the concept map correctly, did not understand the concept map, and could not express themself correctly. In addition, it is thought that the field information available in the teacher candidate was not sufficient to read the concept map. Since the subject of light contains abstract concepts, it is hard to understand for many students and so students have alternative concepts as it is stated in the relevant literature (Bendall et al., 1993; Toh and Boo, 1999; Wittmann et al., 2003). This situation supports the relevant interpretation.

The distribution of the scores of the teacher candidates according to the weak, medium, and good categories is presented in Table 4.

As shown in Table 4, when we look at the scores of the teacher candidates according to the reference text, there were six physics teacher candidates in the weak category of $0-17.34$ points. These teacher candidates constituted $18.75 \%$ of the sample. Teacher candidates who were located in the category of weak had difficulty in establishing relationships between concepts and it could be explained that alternative concepts were resistant to change (Berquest and Heikkinen, 1990). In addition, as Aktaş and Güler (2011) and Dönmez Usta and Ültay (2016) mentioned in their studies, giving the concept map in the research may cause the teacher candidates difficulty in establishing relations between concepts. When the advantages of concept maps were taken into consideration, students could consider the relationship between learned science concepts, visualize the relations between the key concepts in a systematic way, and reflect their understanding through the regulation of

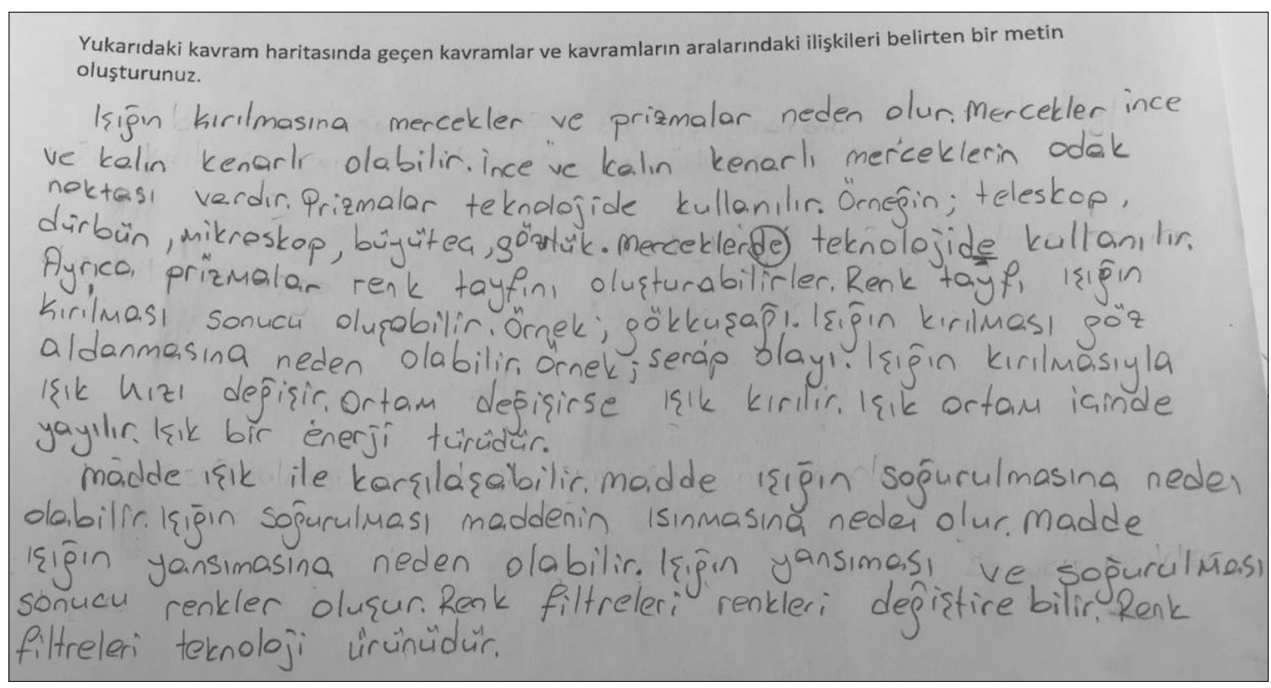

Figure 2: Text generated by T23 with the highest score (in Turkish) 


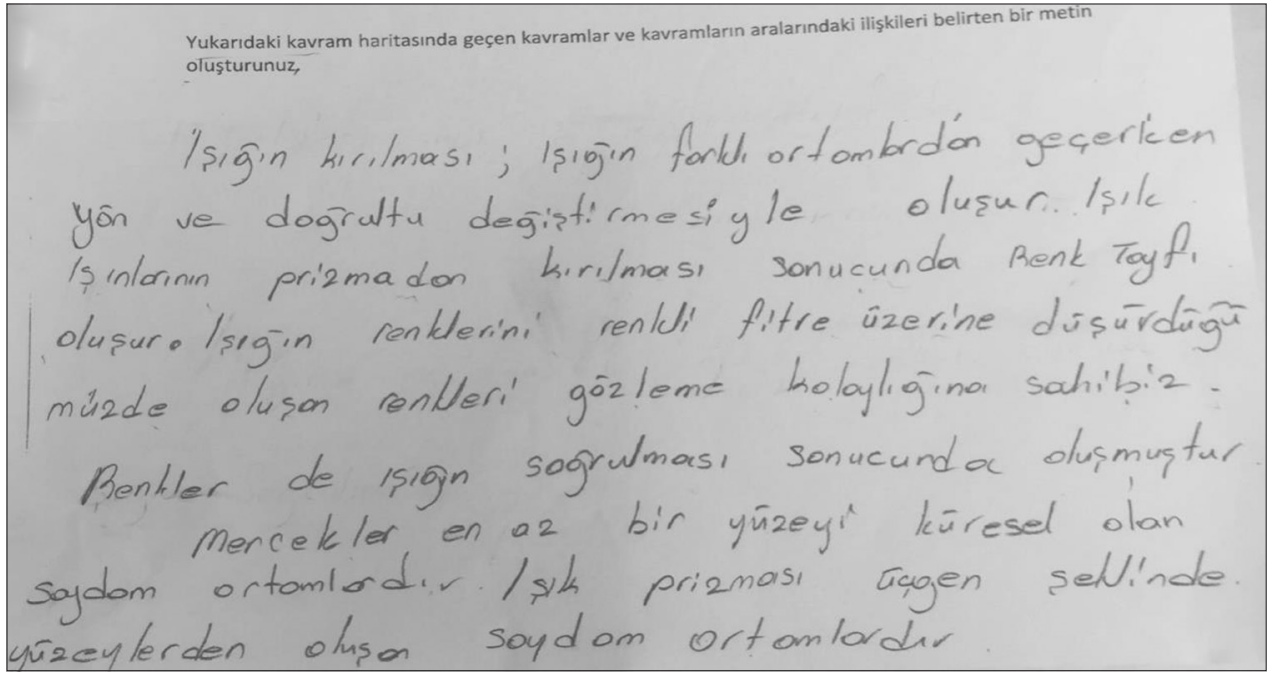

Figure 3: Text generated by T30 with the lowest score (in Turkish)

\begin{tabular}{|c|c|c|c|}
\hline Categories & Mean & Frequency & Percentage \\
\hline $\begin{array}{l}\text { Good } \\
(37.22-40)\end{array}$ & $\mathrm{T} 23$ & 1 & 3.125 \\
\hline $\begin{array}{l}\text { Medium } \\
(17.34-37.22)\end{array}$ & $\begin{array}{c}\mathrm{T} 1, \mathrm{~T} 2, \mathrm{~T} 4, \mathrm{~T} 5, \mathrm{~T} 6, \mathrm{~T} 7, \mathrm{~T} 9, \\
\mathrm{~T} 10, \mathrm{~T} 11, \mathrm{~T} 12, \mathrm{~T} 13, \mathrm{~T} 14, \\
\mathrm{~T} 15, \mathrm{~T} 16, \mathrm{~T} 18, \mathrm{~T} 19, \mathrm{~T} 20, \\
\mathrm{~T} 21, \mathrm{~T} 24, \mathrm{~T} 26, \mathrm{~T} 27, \mathrm{~T} 28, \\
\text { T29, T31, T32 }\end{array}$ & 25 & 78.125 \\
\hline $\begin{array}{l}\text { Weak } \\
(0-17.34)\end{array}$ & T3, T8, T17, T22, T25, T30 & 6 & 18.75 \\
\hline
\end{tabular}

thoughts (Vanides et al., 2005). Thus, the concept map should be read easily for those who have sufficient knowledge of the subject. This situation again brings to mind that the knowledge of the area is not sufficient.

There were 25 physics teacher candidates in the medium category in the 17.34 and 37.22 points range, and there was one in the 37.22 and 40 points range. The teacher candidates in the medium category constituted $78.125 \%$ of the teacher candidates who participated in the study, while the teacher candidate in the good category accounted for only $3.125 \%$. From this finding, it could be said that the vast majority of teacher candidates were able to read the concept map at a medium level. The ability to read concept maps at a medium level could be related to their use of the information contained therein and their preference to read the map. The fact that teacher candidates had forgotten the information they had about light could have made it difficult to read concept maps. This situation could be interpreted as a result of abstract concepts. Students' not being able to make sense of concepts were also related to abstract concepts in science classes (Duit and von Rhöneck, 1997). This relationship is compatible with the abstract concepts of light (Maurines, 1993; Wittmann et al., 2003). It was found that a total of 3-4 h of education was sufficient for teacher candidates to draw and/or read concept maps (Kaya and Ebenezer, 2003) and that they were given adequate training in this study; it is also possible for teacher candidates to not fully understand the concept map reading.

\section{CONCLUSION AND RECOMMENDATIONS}

When the findings obtained from the study were examined, it is concluded that $78.123 \%$ of these physics teacher candidates could read the concept map related to light subjects and concepts at a medium level. Considering the necessity of correct structuring of the relations between concepts and concepts in science education (Ayas, 2005); the importance of the use of concept maps in the learning process is understood. In this case, it is recommended that concept maps be used frequently in learning environments because they are a qualifying tool that helps students to learn more meaningfully (Kinchin et al., 2000). However, considering the studies on the concept map in the literature, it is seen that concept maps are generally used to: Discover the effect of concept maps on science attitudes (Barenholz and Tamir, 1992; Evrekli et al., 2007); eliminate the conceptual misconceptions (Uzuntiryaki and Geban, 1998; Çardak, 2002); investigate the information structures (Ünlü et al., 2006); discover the effects on academic achievement (Ekmekçioğlu, 2007; İnce et al., 2010; Sarıca and Çetin, 2012); and create a concept map (Dönmez Usta and Ültay, 2016). As in this study, it is recommended that studies related to reading concept maps should be studied for different subjects and concepts.

Although the concept map related to light subjects and concepts was used in this study, it was noted that some student teachers did not have enough knowledge of the field to be able to read the map at the medium level. In this case, it is recommended that the concepts related to the subject of light should be increased using different teaching methods and techniques in learning environments. 


\section{REFERENCES}

Aktaş, M., \& Güler, H.K. (2011). The evaluation of concept maps related to the concept of rectangles by form teacher candidates. Gazi University Facultyof Education Journal, 31(2), 605-618.

Ayas, A. (2005). Conceptual learning. In: Çepni, S., (Ed.), Science and Technology Teaching from Theory to Application. Ankara: PegemA Publishing. pp. 174-202.

Bağc1, K.G. (2003). Concept maps and language: A Turkish experience. International Journal of Science Education, 25(11), 1299-1311.

Bak, Z., \& Ayas, A. (2008). Identifying Understanding Levels Related to Atom Concept of Chemistry Students Through Concept Mapping. Paper presented at the $8^{\text {th }}$ International Educational Technology Conference, Anadolu University, Eskişehir-Turkey.

Barenholz, H., \& Tamir, P. (1992). A comprehensive use of concept mapping in design instruction and assessment. Research in Science and Technological Education, 10(1), 37-52.

Bayram, H., Salan, U., \& Gürdal, A. (1999). The Effect of Concept Map on Success in Solutions of Stoichiometric Problems. Paper presented at the National Education Symposium. Marmara University, İstanbul.

Bendall, S., Goldberg, F., \& Galili, I. (1993). Prospective elementary teachers" prior knowledge about light. Journal of Research in Science Teaching, 30(9), 1169-1187.

Berquest, W., \& Heikkinen, H. (1990). Student ideas regarding chemical equilibrium. Journal of Chemical Education, 67(12), 1000-1003.

Büyükkasap, E., \& Samancı, O. (1998). Misconceptions of primary school students about light. Kastamonu Education Journal, 4(5), 109-120.

Çardak, O. (2002). The İdentification of Misconceptions of High Frechmen on the Variety and Classification of Living Things and Correction of them Through Concepts Maps. Unpublished Doctoral Dissertation, Selçuk University, Konya.

Case, J.M., \& Fraser, M. (1999). An investigation into chemical engineering students' understanding of the mole and the use of concrete activities to promote conceptual change. International Journal of Science Education, 21, 1237-1249.

Çepni, S. (2005). Science and Technology Teaching from Theory to Application. $4^{\text {th }}$ ed. Ankara, Turkey: PegemA Publishing.

Çepni, S. (2007). Introduction to Research and Project Work. Trabzon, Turkey: Celepler Printing.

Chang, K., Sung, Y., \& Chen, I. (2002). The effect of concept mapping to enhance text comprehension and summarization. Journal of Experimental Education, 71, 5-23.

Çil, E. (2010). Teaching of the Nature of Science in Conceptual Change Pedagogy and Explicit Reflective Approach: A Case Study for Light Unit. Unpublished Doctoral Dissertation, Karadeniz Technical University, Trabzon.

Cohen, L., \& Manion, L. (1989). Research Methods in Education. $4^{\text {th }}$ ed. New York: Routledge.

Creswell, J.W. (2013), Research Design Qualitative, Quantitative, and Mixed Method Approaches. $4^{\text {th }}$ ed. Thousand Oaks, CA: Sage Publications, Inc.

Dönmez Usta, N., \& Ültay, N. (2015). A comparative study of preschool student teachers" "chemistry" metaphors. The Black Sea Journal of Social Sciences, 7(1), 163-177.

Dönmez Usta, N., \& Ültay, N. (2016). Prospective chemistry teachers' abilities of creating concept maps: Hydrocarbons example. Journal of Baltic Science Education, 15(1), 58-67.

Drew, C.J., Hardman, M.L., Hart, A.W. (1996). Designing and Conducting Research: Inquiry in Education and Social Science. $2^{\text {nd }}$ ed. Boston, MA: Allyn and Bacon.

Duit, R., \& von Rhöneck, C. (1997). Learning and understanding key concepts of electricity. In: Tiberghien, A., Jossem, E.L., Barojas, J., (Eds.), Connecting Research in Physics Education with Teacher Education., Sec. C2. London, UK: International Commission on Physics Education. pp. 46-51.

Ekmekçioğlu, E. (2007). The Effect of Meaningful Learning Theory and Teaching with Concept Map to Achievement of Asid-base Topic in Chemistry Lessons at High Schools. Unpublished Doctoral Dissertation, Selçuk University, Konya.

Evrekli, E., İnel, D., \& Balım, A.G. (2007). The effects of the use of concept and mind map on students' conceptual understandings and attitudes toward science and technology. Abant Izzet Baysal University Journal of Faculty of Education, 12(1), 229-250.

Fencebilim. (2016). Science and Technology [Concept Map of Refraction of Light]. Available from: https://www.fencebilim.com/fen/kavram/isigin. JPG. [Last accessed on 2016 Dec 10].

Güneş, T., Güneş, M.H., \& Çelikler, D. (2006). The effect of concept map using on student succes in the teaching of biology II subjects presented in science teacher programme. Ahi Evran University Journal of Kirşehir Faculty of Education, 7(2), 39-49.

Horton, P.B., McConney, A.A., Gallo, M., Woods, A.L., Senn, G.J., \& Hamelin, D. (1993). An investigation of the effectiveness of concept mapping as an instructional tool. Science Education, 77(1), 95-111.

İnce, E., Güven, E., \& Aydoğdu, M. (2010). The effect of concept map and $\mathrm{V}$ diagram on the academic achievement and permanence in science laboratory lesson. Journal of Çukurova University Institute of Social Sciences, 19(2), 378-394.

Kaptan, F. (1998). Using concept map method in science teaching. Hacettepe University Journal of Education, 14, 95-99.

Kaya, O.N. (2003). An alternative way of assessment in education: Concept maps. Hacettepe University Journal of Education, 25, 265-271

Kaya, O.N., \& Ebenezer, J.V. (2003). A Longitudinal Study of the Effects of Concept Mapping and Vee Diagramming on Senior University Students' Achievement, Attitudes and Perceptions in Science Laboratory. Paper Presented at the Annual Conference of the National Association for Research in Science Teaching (NARST, USA), Philadelphia.

Kilic, M., \& Cakmak, M. (2013). Concept maps as a tool for meaningful learning and teaching in chemistry education. International Journal on New Trends in Education and Their Implications, 4(4), 152-164.

Kinchin, I.M., Hay, D.B., \& Adams, A. (2000). How a qualitative approach to concept map analysis can be used to aid learning by illustrating patterns of conceptual development. Educational Research, 42(1), 43-57.

Landis, J.R., \& Koch, G.G. (1977). The measurement of observer agreement for categorical data. Biometrics, 33(1), 159-174.

Masson, S., \& Vazquez-Abad, J. (2006). Integrating history of science in science education through historical micro worlds to promote conceptual change. Journal of Science Education and Technology, 15, 257-268.

Maurines, L. (1993). Spontaneous reasoning on the propagation of sound. In: Novak, J., (Ed.), Proceedings of the Third International Seminar on Misconceptions and Educational Strategies in Science and Mathematics. Ithaca, New York: Cornell University.

Miles, M.B., \& Huberman, A.M. (1994). Qualitative Data Analysis. $2^{\text {nd }}$ ed. Thousand Oaks, CA: Sage Publications, Inc.

Novak, J., \& Gowin, D.B. (1984). Learning How to Learn. Cambridge, UK: Cambridge University Press.

Okebukola, P.A. (1990). Attaining meaningful learning of concepts in genetics and ecology: An examination of the potency of the concept mapping technique. Journal of Research in Science Teaching, 27(5), 493-504.

Osborne, J., Black, P., Smith, M., \& Meadows, J. (1990). Light (Primary Space Project Research Report). Liverpool: Liverpool University Press.

Öztürk, D.F. (2003). Concept Map's Effective on Student Achivement in Grade 9 Geography Course. Unpublished Master Dissertation, Gazi University, Ankara.

Şahin, F. (2002). A research on the use of concept maps as an assessment tool. Pamukkale University Journal of Education Eğitim Fakültesi Dergisi, 11, 17-32.

Sarıca, R., \& Çetin, B. (2012). The effects of using concept maps on achievement and retention in teaching science lessons. Elementary Education Online, 11(2), 306-318

Sarıçayır, H. (2000). The Effect of Concept Maps to the Achivement Inchemistry Course in Grade 10. Unpublished Master Dissertation, Marmara University, İstanbul.

Shieh, C., \& Yang, Y.T. (2014). Concept Maps Construction Based on Student-problem Chart. In the Proceedings of the IIAI $3^{\text {rd }}$ International Conference on Advanced Applied Informatics (IIAIAAI '14). Kokura Kita-ku, Japan. pp. 324-327.

Toh, K., \& Boo, H. (1999). Students' perspectives in understanding light and vision. Educational Research, 41(2), 155-162.

Turan, O.N. (2016). The Comparision of Different Concept Mapping Tasks 
in Chemistry Education. Unpublished Doctoral Dissertation, Gazi University, Ankara.

Ültay, E. (2017). Examination of context-based problem-solving abilities of pre-service physics teachers. Journal of Baltic Science Education, 16(1), 113-122.

Ültay, E., \& Can, M. (2015). Determination of preschool student teachers' conceptual knowledge about "heat and temperature". The Black Sea Journal of Social Sciences, 7(1), 179-203.

Ünlü, P., İngeç, Ş.K., \& Taşar, M.F. (2006). Investigating teacher candidates' knowledge structures about momentum and impuls by the method of using concept maps. Education and Science, 31(139), 70-79.

Uzuntiryaki, E., \& Geban, Ö. (1998). Using Conceptual Change Texts and Concept Maps in Teaching the Subject of Solution in the $8^{\text {th }}$ Grade. Paper Presented at the National $3^{\text {rd }}$ Science Symposium, Karadeniz Technical University, Trabzon.

Uzuntiryaki, E., Çakır, Ö.S., \& Geban, Ö. (2001). The Effect of Concept Maps and Conceptual Change Texts on Eliminating Students" Misconceptions about Acid Bases. Paper Presented at the Science Education Symposium at the Beginning of the New Millennium,
Maltepe University, İstanbul.

Vanides J., Yue, Y., Tomita, M., \& Ruiz-Primo, M.A. (2005). Using concept maps in the science classroom. Science Scope, 28(8), 27-31.

Vodovozov, V., \& Raud, Z. (2015). Concept Maps for Teaching, Learning, and Assessment in Electronics. Education Research International. Available from: http://www.downloads.hindawi.com/journals/edri/2015/849678. pdf. [Last retrieved on 2020 Jan 31].

Wellington, J. (2000). Educational Research, Contemporary Issues and Practical Approaches. London, UK: Continuum.

White, R., \& Gunstone, R. (1992). Probing Understanding. London, UK: The Falmer Press.

Wittmann, M.C., Steinberg, R.N., \& Redish, E.F. (2003). Understanding and addressing student reasoning about sound. International Journal of Science Education, 25(8), 991-1013.

Wu, Y. (2007). A Pilot Study of Applying Hierarchical Curriculum Structure Graph for Remedial Learning". In the Proceedings of the $7^{\text {th }}$ IEEE International Conference on Advanced Learning Technologies (ICALT '07)., Niigata, Japan. pp. 103-107.,

Yıldırım, A., \& Şimşek, H. (2011). Qualitative Research Method in Social Sciences. $8^{\text {th }}$ ed. Ankara, Turkey: Seçkin Publishing. 